
\title{
R Resarach S Surare \\ The Effect of Acromioplasty or Bursectomy on the Results of Arthroscopic Repair of Full Thickness Rotator Cuff Tears: Does the Acromion Type Affect These Results?
}

Ozgun Karakus ( $D$ ozgunkarakus@hotmail.com )

Fatih Sultan Mehmet Egitim ve Arastirma Hastanesi

Ahmet Sinan Sari

Omer Halisdemir Universitesi

Research article

Keywords: Rotator Cuff Tears, Rotator Cuff Impingement, Shoulder Pain, Bursitis, Acromın

Posted Date: May 18th, 2020

DOI: https://doi.org/10.21203/rs.3.rs-28313/v1

License: (a) This work is licensed under a Creative Commons Attribution 4.0 International License.

Read Full License 


\section{Abstract}

Introduction: The aim of this study was to investigate the effect of subacromial decompression on the results of full thickness rotator cuff repair applied arthroscopically. Examination was also made of the effect of acromion type on the subacromial decompression procedure in patients applied with arthroscopic rotator cuff repair.

Materials and Methods: The study included a total of 150 patients, comprising $102(68 \%)$ females and 48 (32\%) males with a full thickness rotator cuff tear repaired arthroscopically. The patients were separated into 3 groups of 50 . Group A comprised those with acromioplasty and bursectomy applied additional to the repair. In Group B, only bursectomy was performed additional to the repair and in Group C, only rotator cuff repair was applied. Evaluation was made of the postoperative long-term pain and functional results.

Results: The mean age of the cases was $65.63 \pm 9.22$ years (range, $46-86$ years). The affected side was right side in 95 (63.3\%) cases and left side in 55 (36.7\%). No statistically significant difference was determined between the groups according to the postoperative Constant Murley and ASES scores ( $p>0.05$ ). In the paired comparisons, the postoperative VAS scores of Group $C$ were higher than those of Groups $A$ and $B(p=0.018, p=0.029, p<0.05)$. No statistically significant difference was determined between Group A and Group B in respect of the postoperative VAS scores $(p>0.05)$.

Conclusions: In the arthroscopic repair of full thickness rotator cuff tears, neither acromioplasty, coracoacromial ligament loosening nor bursectomy were determined to have any positive effect on the results. Whatever the acromion type, there is no need for an additional subacromial decompression procedure after rotator cuff repair, in respect of pain and functional outcomes. Only acromial spurs should be gently removed paying attention to the coraco-acromial ligament.

\section{Background}

Shoulder pain is described as the second most common musculoskeletal system disorder following lower back pain. Rotator cuff pathology and subacromial impingement are accepted as the leading causes of shoulder pain [1]. Rotator cuff pathologies include partial or full thickness rotator cuff tears, subacromial bursitis, or rotator cuff tendinitis. Subacromial impingement syndrome has ben accepted for many years as the most common reason for rotator cuff pathology. In 1949, Armstrong [2] first suggested that the impingement of bursa and rotator cuff tendons below the acromion caused supraspinatus syndrome. Neer later reported that $95 \%$ of rotator cuff tears were due to mechanical impingement and treatment was successful with partial anterior acromioplasty $[3,4]$.

Arthroscopic acromioplasty is widely used in treatment of subacromial impingement. Despite application in cases not responding to conservative treatment, there are studies in literature reporting that there is no benefit of this procedure other than the additional costs $[5,6]$. 
Generally, there are two theories related to rotator cuff tear and subacromial impingement. These are the mechanical (extrinsic) theory and the degenerative (intrinsic) theory. The mechanical theory defined by Neer states that rotator cuff rupture occurs with the mechanical impingement of the coraco-acromial arch. Authors defending this theory have stated that acromioplasty is indispensible in rotator cuff repair. According to the degenerative theory, a tear forms associated with degeneration in the rotator cuff as a result of ageing and overuse of the shoulder. Those who advocate this theory suggest that acromioplasty is not necessary and the problem can be eliminated with bursectomy alone as all the symptoms and changes observed in the acromion are thought to have developed secondary to degenerative tendinopathy.

Although there are studies and clinical data supporting both theories, no consensus has been reached as yet $[7,8]$.

Recent studies have questioned the role of subacromial impingement in rotator cuff tears. There are studies showing that the effect of partial acromioplasty applied in cases of rotator cuff pathology has not changed the results as much as expected $[9,10,11]$.

There are also studies which have stated coraco-acromial ligament damage as the reason for deltoid detachment. In a cadaver study by Green et al, it was shown that a $4 \mathrm{~mm}$ bone resection made from the acromial surface caused $56 \%$ loosening in the attachment site of the deltoid and a $5.5 \mathrm{~mm}$ bone resection caused $77 \%$ loosening in the deltoid attachment [12].

In contrast, there are also studies that recommend bursectomy only in the treatment of rotator cuff disease and impingement syndrome. These studies suggest that an inflamed and thickened bursa is a major source of pain and creates impingement, therefore bursectomy would be extremely beneficial [13]. In studies related to the shape of the acromion or acromial spurs, a relationship has been determined between these pathologies and rotator cuff tears, but the cause and effect relationship has not been fully revealed [14].

Effective results have been reported of rotator cuff repair applied without acromioplasty or coracoacromial ligament loosening. There are also studies stating that acromioplasty applied together with coraco-acromial ligament loosening could cause an increase in glenohumeral instability $[15,16]$. In contrast, other studies in literature have shown excellent results of rotator cuff repair applied together with subacromial decompression [17].

Therefore, no consensus has yet been reached and the aim of this study was to investigate the effect of subacromial decompression in full thickness rotator cuff repair performed arthroscopically, that is, the effect on the results of anterior-inferior acromioplasty, coraco-acromial ligament loosening and subacromial bursectomy. A different aspect of this study is that evaluation was made separately of the effect on the results of acromioplasty, coraco-acromial ligament release and subacromial bursectomy. In addition, it was examined whether the subacromial decompression procedure showed any difference 
according to the acromion type in patients applied with arthroscopic rotator cuff repair, or whether evaluation should be made independently of acromion type.

\section{Method}

This study has been performed by Omer Halisdemir University Hospital Department of Orthopedics and Traumatology, with the T.R. Kayseri Erciyes University Local Ethics Committee decision dated 10/12/2019 No:57

The study included a total of 150 patients applied with arthroscopic full thickness rotator cuff repair, comprising $102(68 \%)$ females and $48(32 \%)$ males with a mean age of $65.63 \pm 9.22$ years (range, 4686 years). The affected side was right side in 95 (63.3\%) cases and left side in 55 (36.7\%). Patients were excluded if they had shoulder instability, glenohumeral joint degenerative arthritis, acromioclavicular pathology, tuberculum fracture, a history of shoulder surgery because of fracture, or if arthroscopic repair was applied again because of re-rupture following primary repair.

All the patients had a full thickness, crescent type tear. In all cases, arthroscopic examination was made of the glenohumeral joint, and no additional pathology was determined on the long biceps head. The patients were separated into 3 groups of 50 . Group A comprised those applied with arthroscopic rotator cuff repair, bursectomy, coraco-acromial ligament loosening and antero-inferior acromioplasty. In Group B, arthroscopic rotator cuff repair was applied with bursectomy only and no acromioplasty. In Group C, only rotator cuff repair was applied with no additional subacromial decompression procedure. In Groups $\mathrm{B}$ and $\mathrm{C}$, any acromial spurs determined during arthroscopy were lightly corrected with a burr, but patients with type III acromion could not be converted to type I and II acromion.

With preoperative magnetic resonance imaging (MRI) and x-ray examinations of all patients, the subacromial area, acromion type, (according to Bigliani on MRI scans: type I- flat, type II-curved, type IIIhooked) and full rotator cuff pathology were determined and recorded. All patients were evaluated preoperatively with measurement of ROM, the Constant Murley Score (CM), the American Shoulder and Elbow Surgeons score (ASES) and Visual Analog Score (VAS) for pain, and the results were recorded.

The mean follow-up period was 36.2 months (range, 26-51 months). At the final follow-up examination, all the patients were again evaluated again with the CM, ASES and VAS scores, and the acromion type was measured again. These values were compared with the preoperative values. All the tests at the final follow-up examination were applied by the same doctor. Differences between the groups were examined in respect of the shoulder function and pain scores.

\section{Surgical Technique}

Prophylaxis of $1000 \mathrm{gr}$ cefazol was administered, then under general anaesthesia the patients were placed in the beach-chair position. Following the necessary draping and staining procedures, a posterior 
portal was opened and arthroscopic examination of the glenohumeral joint was made. Then entering the subacromial space, first a smooth opening and visualization was obtained with radiofrequency and a shaver, then the rotator cuff tear was visualized. By determining the footprint, the rotator cuff was compressed with a $4.5 \mathrm{~mm}$ titanium anchor (Arthrex ${ }^{\circledR}$, Smith and Nephew ${ }^{\circledR}$ ) using the lateral portal. With the tension band method, double row repair was made using a $4.5 \mathrm{~mm}$ pushLock anchor. In Group A patients, following bursectomy with the aid of radiofrequency and a shaver, coraco-acromial ligament loosening and antero-inferior acromioplasty using a $4 \mathrm{~mm}$ burr were also applied. To the patients in Group B, only bursectomy was applied.

The same postoperative follow-up protocol was applied to all the patients in all the groups. Passive shoulder movements were started on postoperative day 1. For 6 weeks, a shoulder-arm sling supporting abduction was worn and active shoulder movement was restricted for 6 weeks. The sling was removed

after 6 weeks, and a physical therapy program was applied in respect of active shoulder movements for 2 months. No complications were observed in any patient throughout the postoperative follow-up period.

\section{Statistical Analyses}

Data obtained in the study were analysed statistically using NCSS software (Number Cruncher Statistical System, 2007, Kaysville, Utah, USA). When evaluating the data descriptive statistical methods were used and results were stated as mean \pm standard deviation (SD), median, minimum and maximum values, number (n), and percentage (\%). Conformity of quantitative data to normal distribution was assessed with the Kolmogorov-Smirnov test, the Shapiro-Wilk test and graphically. In the comparison of 3 or more groups of data showing normal distribution, the One-Way ANOVA test was used, and if not conforming to normal distribution, the Kruskal Wallis test. In paired comparisons the Bonferroni-Dunn test was applied. In the comparison of qualitative data, the Pearson Chi-square test was used. In the within group comparisons, the Paired Samples t-test was applied to parameters showing normal distribution and the Wilcoxon Signed Rank test to parameters not showing normal distribution. The Homogeneity test was applied in the evaluation of preoperative and postoperative acromion types. A value of $p<0.05$ was accepted as statistically significant.

\section{Results}

Evaluation was made of a total of 150 patients applied with arthroscopic full thickness rotator cuff repair, comprising $102(68 \%)$ females and $48(32 \%)$ males with a mean age of $65.63 \pm 9.22$ years (range, 4686 years). The affected side was right side in 95 (63.3\%) cases and left side in $55(36.7 \%)$.

No statistically significant difference was determined between the groups in respect of age and gender distribution or the operated side $(p>0.05)$ (Table 1$)$. 
Table 1

Demographic Characteristics according to the Groups.

$\begin{array}{lllll}\begin{array}{l}\text { Total (n } \\ =150)\end{array} & \begin{array}{l}\text { Group A } \\ (n=50)\end{array} & \begin{array}{l}\text { Group B } \\ (n=50)\end{array} & \begin{array}{l}\text { Group C } \\ (n=50)\end{array} & p\end{array}$

\section{Constant Murley Score}

Preoperative

$\begin{array}{llllll}\text { Min-Max } & 35-48 & 35-48 & 36-48 & 36-48 & \text { a } 0.875 \\ (\text { Median) } & (39) & (39) & (39) & (39) & \\ \text { mean } \pm \text { SD } & 39.55 \pm & 39.68 \pm & 39.54 \pm & 39.44 \pm & \\ & 2.32 & 2.60 & 2.30 & 2.07\end{array}$

Postoperative

$\begin{array}{llllll}\text { Min-Max } & 72-89 & 76-89 & 72-87 & 72-89 & { }^{\mathrm{a}} 0.470 \\ (\text { Median) } & (80) & (80) & (80) & (82) & \end{array}$

mean $\pm S D$

$81.12 \pm$

$81.00 \pm$

$80.86 \pm$

$81.50 \pm$ 2.73

2.49

2.61

3.06

${ }^{d} p$

$0.001^{\star *}$

$0.001^{\star *}$

$0.001^{\star *}$

\section{Preoperative -} postoperative difference

\begin{tabular}{llllll|} 
Min-Max & $32-50$ & $32-$ & $32-49$ & $32-50$ & ${ }^{\mathrm{a}} 0.443$ \\
$($ Median) & $(42)$ & $49(41.5)$ & $(42)$ & $(42)$ & \\
mean \pm SD & $41.57 \pm$ & $41.32 \pm$ & $41.32 \pm$ & $42.06 \pm$ \\
& 3.33 & 3.33 & 3.15 & 3.52 &
\end{tabular}

\section{ASES Score}

Preoperative

Postoperative

\begin{tabular}{|c|c|c|c|c|c|}
\hline $\begin{array}{l}\text { Min-Max } \\
\text { (Median) }\end{array}$ & $\begin{array}{l}20-32 \\
(24)\end{array}$ & $\begin{array}{l}20-32 \\
(23)\end{array}$ & $\begin{array}{l}20-32 \\
(23)\end{array}$ & $\begin{array}{l}21-32 \\
(25)\end{array}$ & a 0.975 \\
\hline mean $\pm S D$ & $\begin{array}{l}24.07 \pm \\
2.83\end{array}$ & $\begin{array}{l}24.10 \pm \\
2.83\end{array}$ & $\begin{array}{l}24.00 \pm \\
2.98\end{array}$ & $\begin{array}{l}24.12 \pm \\
2.72\end{array}$ & \\
\hline $\begin{array}{l}\text { Min-Max } \\
\text { (Median) }\end{array}$ & $\begin{array}{l}68-93 \\
(80)\end{array}$ & $\begin{array}{l}70-93 \\
(80)\end{array}$ & $\begin{array}{l}68-93 \\
(80)\end{array}$ & $\begin{array}{l}70-93 \\
(80)\end{array}$ & ${ }^{\mathrm{a}} 0.881$ \\
\hline mean $\pm S D$ & $\begin{array}{l}79.89 \pm \\
4.14\end{array}$ & $\begin{array}{l}79.90 \pm \\
3.68\end{array}$ & $\begin{array}{l}79.68 \pm \\
3.94\end{array}$ & $\begin{array}{l}80.10 \pm \\
4.80\end{array}$ & \\
\hline$d_{p}$ & & $0.001^{\star \star}$ & $0.001^{\star *}$ & $0.001^{\star \star}$ & \\
\hline $\begin{array}{l}\text { Min-Max } \\
\text { (Median) }\end{array}$ & $\begin{array}{l}41-72 \\
(56)\end{array}$ & $\begin{array}{l}48-71 \\
(56)\end{array}$ & $\begin{array}{l}46-72 \\
(56)\end{array}$ & $\begin{array}{l}41-72 \\
(56)\end{array}$ & ${ }^{\mathrm{a}} 0.955$ \\
\hline mean $\pm S D$ & $\begin{array}{l}55.82 \pm \\
4.94\end{array}$ & $\begin{array}{l}55.80 \pm \\
4.25\end{array}$ & $\begin{array}{l}55.68 \pm \\
4.64\end{array}$ & $\begin{array}{l}55.98 \pm \\
5.88\end{array}$ & \\
\hline
\end{tabular}

VAS Score

${ }^{a}$ One-way ANOVA Test ${ }^{b}$ Pearson Chi-square Test ${ }^{*} p<0.05{ }^{* *} p<0.01$

${ }^{c}$ Kruskal Wallis Test ${ }^{d}$ Paired Samples t Test ${ }^{e}$ Wilcoxon Signed Ranks Test 


\begin{tabular}{|c|c|c|c|c|c|c|}
\hline & & $\begin{array}{l}\text { Total }(n \\
=150)\end{array}$ & $\begin{array}{l}\text { Group A } \\
(n=50)\end{array}$ & $\begin{array}{l}\text { Group B } \\
(n=50)\end{array}$ & $\begin{array}{l}\text { Group C } \\
(n=50)\end{array}$ & $p$ \\
\hline \multirow[t]{2}{*}{ Preoperative } & $\begin{array}{l}\text { Min-Max } \\
\text { (Median) }\end{array}$ & $\begin{array}{l}4-10 \\
(8)\end{array}$ & $4-9(8)$ & $4-9(8)$ & $\begin{array}{l}5-10 \\
(8)\end{array}$ & ${ }^{\circ} 0.332$ \\
\hline & mean $\pm S D$ & $\begin{array}{l}7.51 \pm \\
1.19\end{array}$ & $\begin{array}{l}7.56 \pm \\
1.13\end{array}$ & $\begin{array}{l}7.32 \pm \\
1.24\end{array}$ & $\begin{array}{l}7.66 \pm \\
1.19\end{array}$ & \\
\hline \multirow[t]{3}{*}{ Postoperative } & $\begin{array}{l}\text { Min-Max } \\
\text { (Median) }\end{array}$ & $1-7(2)$ & $1-4(1)$ & $1-4(1)$ & $1-7(2)$ & ${ }^{c} 0.032^{\star}$ \\
\hline & mean $\pm S D$ & $\begin{array}{l}1.79 \pm \\
1.11\end{array}$ & $\begin{array}{l}1.56 \pm \\
0.73\end{array}$ & $\begin{array}{l}1.60 \pm \\
0.78\end{array}$ & $\begin{array}{l}2.22 \pm \\
1.52\end{array}$ & \\
\hline & $e_{p}$ & & $0.001^{\star \star}$ & $0.001^{\star *}$ & $0.001^{\star \star}$ & \\
\hline \multirow{2}{*}{$\begin{array}{l}\text { Preoperative - } \\
\text { postoperative } \\
\text { difference }\end{array}$} & $\begin{array}{l}\text { Min-Max } \\
\text { (Median) }\end{array}$ & $\begin{array}{l}-9--2 \\
(-6)\end{array}$ & $\begin{array}{l}-8--2 \\
(-6)\end{array}$ & $\begin{array}{l}-8--2 \\
(-6)\end{array}$ & $\begin{array}{l}-9--2 \\
(-6)\end{array}$ & ${ }^{\circ} 0.175$ \\
\hline & mean $\pm S D$ & $\begin{array}{l}-5.72 \pm \\
1.49\end{array}$ & $\begin{array}{l}-6.00 \pm \\
1.34\end{array}$ & $\begin{array}{l}-5.72 \pm \\
1.50\end{array}$ & $\begin{array}{l}-5.44 \pm \\
1.61\end{array}$ & \\
\hline Acromion Type & $n(\%)$ & & & & & \\
\hline \multirow[t]{3}{*}{ Preoperative } & Type 1 & $\begin{array}{l}59 \\
(39.3)\end{array}$ & $20(40.0)$ & $22(44.0)$ & $17(34.0)$ & $\mathrm{b}_{0.771}$ \\
\hline & Type 2 & $\begin{array}{l}63 \\
(42.0)\end{array}$ & $19(38.0)$ & $20(40.0)$ & $24(48.0)$ & \\
\hline & Type 3 & $\begin{array}{l}28 \\
(18.7)\end{array}$ & $11(22.0)$ & $8(16.0)$ & $9(18.0)$ & \\
\hline \multirow[t]{3}{*}{ Postoperative } & Type 1 & $\begin{array}{l}61 \\
(40.7)\end{array}$ & $24(48.0)$ & $20(40.0)$ & $17(34.0)$ & ${ }^{b} 0.101$ \\
\hline & Type 2 & $\begin{array}{l}71 \\
(47.3)\end{array}$ & $25(50.0)$ & $22(44.0)$ & $24(48.0)$ & \\
\hline & Type 3 & $\begin{array}{l}18 \\
(12.0)\end{array}$ & $1(2.0)$ & $8(16.0)$ & 9 (18.0) & \\
\hline \multicolumn{7}{|c|}{${ }^{a}$ One-way ANOVA Test ${ }^{b}$ Pearson Chi-square Test ${ }^{*} p<0.05 * * p<0.01$} \\
\hline
\end{tabular}

In the evaluation of the Constant Murley (CM) scores, no statistically significant difference was determined between the groups in respect of the preoperative and postoperative CM scores $(p>0.05)$. In Groups $A, B$ and $C$, a statistically significant increase was determined in the postoperative $C M$ scores compared to the preoperative values $(p=0.001, p<0.05$, for all). No statistically significant difference was determined between the groups in respect of the change in the $\mathrm{CM}$ score from preoperative to postoperative $(p>0.05)$ (Table 2$)$. 
Table 2

Evaluation of Constant Murley, ASES, VAS Scores and Acromion Types according to the Groups.

\begin{tabular}{|c|c|c|c|c|c|c|}
\hline & \multirow{2}{*}{$\begin{array}{l}\text { Postoperative } \\
\text { Acromion } \\
\text { type }\end{array}$} & \multirow{2}{*}{$\mathrm{N}$} & \multicolumn{3}{|c|}{ Postoperative VAS Score } & \multirow[t]{2}{*}{$p$} \\
\hline & & & Mean & SD & Min-Max (median) & \\
\hline \multirow[t]{3}{*}{ Group A } & Type 1 & 24 & 1.88 & 0.80 & $1-4(2)$ & \\
\hline & Type 2 & 25 & 1.28 & 0.54 & $1-3(1)$ & $0.003^{\star \star}$ \\
\hline & Type 3 & 1 & 1.00 & . & $1-1(1)$ & \\
\hline \multirow[t]{4}{*}{ Group B } & Type 1 & 20 & 1.95 & 0.89 & $1-4(2)$ & \\
\hline & Type 2 & 22 & 1.23 & 0.43 & $1-2(1)$ & $0.011^{*}$ \\
\hline & Type 3 & 8 & 1.75 & 0.89 & $1-3(1.5)$ & \\
\hline & Total & 50 & 1.60 & 0.78 & $1-4(1)$ & \\
\hline \multirow[t]{3}{*}{ Group C } & Type 1 & 17 & 1.94 & 0.75 & $1-3(2)$ & \\
\hline & Type 2 & 24 & 1.58 & 0.65 & $1-3(1.5)$ & $0.002^{\star \star}$ \\
\hline & Type 3 & 9 & 4.44 & 2.19 & $1-7(5)$ & \\
\hline
\end{tabular}

In the evaluation of the ASES scores, no statistically significant difference was determined between the groups in respect of the preoperative and postoperative ASES scores $(p>0.05)$. In Groups A, B and C, a statistically significant increase was determined in the postoperative ASES scores compared to the preoperative values $(p=0.001, p<0.05$, for all). No statistically significant difference was determined between the groups in respect of the change in the ASES score from preoperative to postoperative ( $p>$ 0.05) (Table 2).

In the evaluation of the VAS scores, no statistically significant difference was determined between the groups in respect of the preoperative and postoperative VAS scores $(p>0.05)$. A statistically significant increase was determined between the groups in respect of the postoperative VAS scores $(p=0.032, p<$ 0.05). As a result of the paired comparisons, the postoperative VAS scores of Group $C$ were determined to be statistically significantly higher than those of Groups $A$ and $B(p=0.018, p=0.029 ; p<0.05)$. No statistically significant difference was determined between the postoperative VAS scores of Group $A$ and Group B ( $p>0.05)$. In Groups A, B and C, the decrease in the postoperative VAS scores compared to the preoperative values was determined to be statistically significant $(p=0.001 ; p<0.05$ for all). No statistically significant difference was determined between the groups in respect of the change in the VAS score from preoperative to postoperative $(p>0.05)$ (Table 2$)$. 
In the evaluation of the postoperative VAS scores according to acromion type;

In Group A, when the postoperative VAS scores were evaluated according to postoperative acromion type, the VAS score of cases with type I acromion was determined to be statistically significantly higher than that of cases with type II acromion $(p<0.01)$.

In Group B, a statistically significant difference was determined in postoperative VAS scores according to acromion type $(p: 0.011 ; p<0.05)$. The VAS scores of cases with type I acromion were determined to be statistically significantly higher than those of cases with type II acromion ( $p: 0.09 ; p<0.01)$. No statistically significant difference was determined between the VAS scores of other types $(p>0.05)$.

In Group C, a statistically significant difference was determined in postoperative VAS scores according to acromion type ( $\mathrm{p}: 0.011 ; \mathrm{p}<0.05)$. When significance was examined with the Dunn test, the postoperative VAS scores of cases with type III acromion were determined to be statistically significantly higher than those of cases with type I and type II acromion (p:0.021; p:0.001). No statistically significant difference was determined between type I and type II $(p>0.05)$ (Table 3$)$. 
Table 3

Evaluation of Postoperative VAS scores according to Postoperative Acromion types.

\begin{tabular}{|c|c|c|c|c|c|c|}
\hline \multirow[t]{3}{*}{ Groups } & \multirow{3}{*}{$\begin{array}{l}\text { Postoperative Acromion } \\
\text { Type }\end{array}$} & \multicolumn{4}{|c|}{ Preoperative Acromion Type } & \multirow[t]{3}{*}{$p$} \\
\hline & & Type 1 & Type 2 & Type 3 & Total & \\
\hline & & $\mathrm{n}(\%)$ & $\mathrm{n}(\%)$ & $\mathrm{n}(\%)$ & $\mathrm{n}(\%)$ & \\
\hline \multirow[t]{4}{*}{$\begin{array}{l}\text { Group } \\
\text { A }\end{array}$} & Type 1 & $\begin{array}{l}14 \\
(28.0)\end{array}$ & $6(12.0)$ & $4(8.0)$ & $24(48.0)$ & $0.016 *$ \\
\hline & Type 2 & $6(12.0)$ & $13(26.0)$ & $6(12.0)$ & $25(50.0)$ & \\
\hline & Type 3 & $0(0)$ & $0(0)$ & $1(2.0)$ & $1(20.0)$ & \\
\hline & Total & $\begin{array}{l}20 \\
(40.0)\end{array}$ & $19(38.0)$ & $11(22.0)$ & $50(100.0)$ & \\
\hline \multirow[t]{4}{*}{$\begin{array}{l}\text { Group } \\
\text { B }\end{array}$} & Type 1 & $\begin{array}{l}20 \\
(40.0)\end{array}$ & $0(0)$ & $0(0)$ & $20(40.0)$ & 0.157 \\
\hline & Type 2 & $2(4.0)$ & $20(40.0)$ & $0(0)$ & $22(44.0)$ & \\
\hline & Type 3 & $0(0)$ & $0(0)$ & $8(16.0)$ & $8(16.0)$ & \\
\hline & Total & $\begin{array}{l}22 \\
(44.0)\end{array}$ & $20(40.0)$ & $8(16.0)$ & $50(100.0)$ & \\
\hline \multirow[t]{4}{*}{$\begin{array}{l}\text { Group } \\
\text { C }\end{array}$} & Type 1 & $\begin{array}{l}17 \\
(34.0)\end{array}$ & $0(0)$ & $0(0)$ & $17(34.0)$ & 1.000 \\
\hline & Type 2 & $0(0)$ & $24(48.0)$ & $0(0)$ & $24(48.0)$ & \\
\hline & Type 3 & $0(0)$ & $0(0)$ & $9(18.0)$ & $9(18.0)$ & \\
\hline & Total & $\begin{array}{l}17 \\
(34.0)\end{array}$ & $24(48.0)$ & $9(18.0)$ & $50(100.0)$ & \\
\hline
\end{tabular}

In Group $A$, the change in acromion type from preoperative to postoperative was found to be statistically significant $(p=0.016 ; p<0.05)$.

Preoperatively, acromion type was type I in 20 cases, type II in 19 cases, and type III in 11 cases. Postoperatively, acromion type was type I in 24 cases, type II in 25 cases, and type III in 1 case.

Of the 20 cases with preoperative type I acromion, 14 remained as type I postoperatively, and 6 changed to type II. Of the 19 cases with type II acromion preoperatively, 13 remained as type II postoperatively, and 6 changed to type I. Of the 11 cases with preoperative type III acromion, 1 remained as type III postoperatively, 4 changed to type I and 6 to type II. 
In Group B, the change in acromion type from preoperative to postoperative was not found to be statistically significant $(p=0.157 ; p>0.05)$.

Preoperatively, acromion type was type I in 22 cases, type II in 20 cases, and type III in 8 cases.

Postoperatively, acromion type was type I in 20 cases, type II in 22 cases, and type III in 8 cases.

Of the 22 cases with preoperative type I acromion, 20 remained as type I postoperatively, and 2 changed to type II. All the 20 cases with type II acromion preoperatively remained as type II postoperatively. All the 8 cases with preoperative type III acromion remained as type III postoperatively.

In Group $C$, the change in acromion type from preoperative to postoperative was not found to be statistically significant $(p=1.000 ; p>0.05)$.

All the 17 cases with preoperative type I acromion remained as type I postoperatively. All the 24 cases with type II acromion preoperatively remained as type II postoperatively. All the 9 cases with preoperative type III acromion remained as type III postoperatively (Table 4).

Table 4

Within Group Evaluations of Preoperative and Postoperative Acromion Types.

\begin{tabular}{|c|c|c|c|c|c|c|}
\hline & & $\begin{array}{l}\text { Total }(n= \\
150)\end{array}$ & $\begin{array}{l}\text { Group A }(n= \\
50)\end{array}$ & $\begin{array}{l}\text { Group B }(n= \\
50)\end{array}$ & $\begin{array}{l}\text { Group C }(\mathrm{n}= \\
50)\end{array}$ & $p$ \\
\hline \multirow[t]{2}{*}{$\begin{array}{l}\text { Age } \\
\text { (years) }\end{array}$} & $\begin{array}{l}\text { Min-Max } \\
\text { (Median) }\end{array}$ & $\begin{array}{l}46-86 \\
(65.5)\end{array}$ & $48-81(67)$ & $46-81(65)$ & $46-86(61)$ & ${ }^{\mathrm{a}} 0.786$ \\
\hline & mean $\pm S D$ & $\begin{array}{l}65.63 \pm \\
9.22\end{array}$ & $66.36 \pm 8.81$ & $65.40 \pm 9.60$ & $65.14 \pm 9.36$ & \\
\hline \multirow{2}{*}{$\begin{array}{l}\text { Gender, } n \\
(\%)\end{array}$} & Female & $102(68.0)$ & $30(60.0)$ & $36(72.0)$ & $36(72.0)$ & ${ }^{b} 0.332$ \\
\hline & Male & $48(32.0)$ & $20(40.0)$ & $14(28.0)$ & $14(28.0)$ & \\
\hline \multirow{2}{*}{$\begin{array}{l}\text { Side; } n \\
(\%)\end{array}$} & Right & $95(63.3)$ & $35(70.0)$ & $25(50.0)$ & $35(70.0)$ & b 0.057 \\
\hline & Left & $55(36.7)$ & $15(30.0)$ & $25(50.0)$ & $15(30.0)$ & \\
\hline
\end{tabular}

\section{Discussion}

For many years, subacromial impingement syndrome has been shown to be the reason for rotator cuff pathology. Although there are studies showing that acromial spurs and acromion types are related to rotator cuff pathology, this has not been fully proven. There are also studies that have stated that rather than the type of acromion, other factors cause the impingement in the formation of rotator cuff pathology [18-21]. 
Studies in literature by authors supporting the extrinsic theory have stated that routine application of acromioplasty both improves the arthroscopic visualisation and induces healing of the bleeding from the bone which occurs with the acromioplasty in the subacromial space [22, 23].

In contrast, those who support the intrinsic theory have suggested that preserving the coraco-acromial ligament in respect of glenohumeral stability both reduces costs and shortens operating time and there is no need for acromioplasty following successful rotator cuff repair [24, 25].

No consensus has been reached in literature as yet. The aim of the current study was to show whether or not there was any benefit of subacromial decompression according to acromion type in patients applied with rotator cuff repair. Evaluation was made of 150 patients with the Constant Murley score, the American Shoulder and Elbow Surgeons score and the VAS score for pain.

When evaluations were made in respect of the $\mathrm{CM}$ score, there was a significant difference between the preoperative and postoperative scores of all the groups $(p=0.001, p<0.05)$. However, there was no difference between the postoperative scores of the three groups $(p>0.05)$. This demonstrated that all the groups benefitted from surgery. The application of acromioplasty or bursectomy without acromioplasty or not making any additional procedure other than rotator cuff repair was seen not to make any difference in respect of the $\mathrm{CM}$ score after rotator cuff repair.

There was a significant difference between the preoperative and postoperative ASES scores of all the groups $(p=0.001, p<0.05)$. However, there was no difference between the postoperative ASES scores of the three groups $(p>0.05)$. This demonstrated that all the groups benefitted from surgery. Thus the application of acromioplasty, bursectomy, or no subacromial bursectomy procedure following rotator cuff repair was not seen to make any significant difference in respect of the ASES score. There are similar results in literature $[26,27]$.

However, when the VAS scores were evaluated, a significant difference was determined between the groups in respect of the postoperative VAS scores $(p=0.032, p<0.05)$. The point of interest here is that there was no statistically significant difference between the group applied with acromioplasty additional to the rotator cuff repair (Group A) and the group where only bursectomy was performed after the repair (Group B) ( $p>0.05)$. Irrespective of acromion type, acromioplasty or bursectomy applied in addition to rotator cuff repair made no difference in respect of the VAS scores. However, the postoperative VAS scores of the group not applied with any subacromial decompression procedure in addition to rotator cuff repair (Group C) were significantly higher than those of Groups A and B $(p=0.018, p=0.029 ; p<0.05)$. When Group $C$ was examined, the patients with high postoperative VAS scores were seen to be those with type III acromion (p:0.021, p:0.001). No significant difference was seen between the cases with type I and type II acromion in respect of postoperative VAS scores $(p>0.05)$ (Table 2$)$.

In Group A, when the VAS scores were evaluated according to acromion type, the VAS scores of cases with type I acromion were determined to be significantly higher than those of cases with type II acromion $(p<0.01)$. 
A significant difference was determined in Group B when the postoperative VAS scores were evaluated according to acromion type ( $\mathrm{p}: 0.011, \mathrm{p}<0.05)$. The VAS scores of the cases with type I acromion were determined to be significantly higher than those of cases with type II acromion ( $p: 0.009, p<0.01)$. No significant difference was determined between the other acromion types in this group in respect of postoperative VAS scores $(p>0.05)$ (Table 3$)$.

Finally, it was clear that acromion type showed no correlation with the VAS score. While the VAS scores of cases with type I acromion in Groups A and B were higher than those of the cases with type II, in Group C the highest VAS scores were in cases with type III acromion. Similar results have been reported in some previous studies [28].

Although this shows that antero-inferior acromioplasty or bursectomy applied without being aggressive after rotator cuff repair in patients with type III acromion provided a benefit in respect of the pain score, there was still seen to be no correlation between VAS score and acromion type. Previous studies have shown results that the shoulder scores of cases with type III acromion were worse than those of type I acromion [29].

As no consensus has been reached on this subject in literature, the cause and effect relationship has not been revealed. In the current study, type III acromion only affected the postoperative VAS score, and did not seem to affect the ASES and CM scores. Furthermore, there was no correlation of clinical significance between the postoperative acromion type and VAS score. This could be attributed to the VAS score not being a functional score, but an isolated pain score, and as it is a highly subjective scoring of pain, can vary from person to person.

However, the decrease in VAS scores from preoperative to postoperative was found to be statistically significant in all the groups $(p=0.001, p<0.05)$. Thus, it can be said that all the groups benefitted from the surgery, and this benefit seems to be clearly related to the rotator cuff repair.

Very interesting results emerged from evaluating the preoperative and postoperative acromion types of the patients. In Group A where acromioplasty was applied in addition to rotator cuff repair, of the 20 cases with type I acromion preoperatively, 14 cases remained as type I postoperatively and 6 cases changed to type II. Of the 19 cases with preoperative type II acromion, 13 remained as type II postoperatively and 6 changed to type I. Of the 11 cases with preoperative type III acromion, only 1 case remained type III postoperatively, 4 changed to type I and 6 to type II (Table 4).

When performing acromioplasty in Group A, the target was to convert type II and type III acromions to type I. The target in type I acromions, because of the narrowed subacromial space, was only to remove acromial spurs. In the measurements taken after approximately 3 years, a third of the type I acromions had changed to type II, and the majority of type II acromions remained as type II. By applying acromioplasty to convert to type I acromion, only 1 of the type III acromions remained as type III and the majority changed to type II. Together with ageing, there seems to be the formation of new bone in the site of the resected bone piece. This could show that within years of aggressively applied acromioplasty, the 
formation of new bone is induced and this does not have a very positive effect on functional scores. There are studies in literature showing that the acromion type changed within years after acromioplasty [28].

In Group B, where only bursectomy was applied in addition to rotator cuff repair, of the 22 cases with preoperative type I acromion, 20 cases remained as type I postoperatively and 2 changed to type II. All the 20 preoperative type II cases remained as type II postoperatively, and all the 8 preoperative type III cases also remained as type III postoperatively.

In Group C where only rotator cuff repair was applied, all the 17 preoperative type I acromion cases remained as type I postoperatively. The 24 preoperative acromion type II cases all remained as type II postoperatively and the 9 preoperative type III cases also all remained as type III postoperatively.

The acromion morphology is known to change with age and an increase is seen in type III acromion together with ageing. However, the majority of patients with type III acromion are asymptomatic and the presence of type III acromion alone is not sufficient for the formation of impingement syndrome [30]. According to the results of the current study, following intervention to the subacromial area such as acromioplasty, there clearly seems to be a change occurring in the acromion type which is induced by new bone formation.

In conclusion, the change of acromion type is not of great importance in a clinical sense, and over time, the bone which has been taken may form again. No subacromial decompression procedure applied in addition to rotator cuff repair seems to have a positive effect on results. In the presence of acromial spurs only, gentle spur excision can be performed, but the target should never be to change acromion type.

When Group C, where rotator cuff repair only was performed, was compared with the other groups, no significant difference was determined in all the functional scores. Only when evaluations were made in respect of the VAS scores, the scores of the patients with type III acromion were determined as high compared to the other groups and the cases with type I and type II acromion in Group C. However, as can be seen in the same table (Table 3), in the evaluations of postoperative VAS scores according to postoperative acromion types in Groups A and B, the VAS scores of cases with type I acromion were determined as statistically significantly higher than those of cases with type II acromion $(p<0.01)$.

No significant difference was found between the groups in respect of the postoperative CM and ASES scores, but there were differences in the VAS scores. As the CM and ASES scores provide a more detailed evaluation in respect of both function and pain, they are thought to be more accurate results. That no correlation was seen between VAS score and acromion type can be explained by it being a completely subjective evaluation [28].

\section{Conclusion}


In conclusion, the results of this study showed that neither acromioplasty, nor coraco-acromial ligament release, nor bursectomy were determined to have a positive effect on the results of the arthroscopic repair of full thickness rotator cuff tears. Following rotator cuff repair, whatever the acromion type, there is no need for the application of any additional subacromial decompression procedure in respect of pain and functional outcome. When there are only acromial spurs, these should be gently removed, paying attention to the coraco-acromial ligament. The aim in acromioplasty should never be to convert type II and type III acromions to type I. The aggressive application of acromioplasty was seen to induce new bone formation over time.

\section{Abbreviations}

ASES

American Shoulder and Elbow Surgeons score.

$\mathrm{CM}$

Constant Murley Score.

VAS

Visual Analog Score.

ROM

Range of motion.

MRI

Magnetic resonance imaging.

\section{Declarations}

\section{Ethical Approval and Consent to participate}

Ethical approval was obtained by T.R. Kayseri Erciyes University Ethics Committee 10/12/2019 No:57 Consent to participate was obtained from the participants.

\section{Consent for publication}

Written informed consent for publication of their clinical details and/or clinical images was obtained from the patient. A copy of the consent form is available for review by the Editor of this journal.

\section{Availability of supporting data}

Applicable. 


\section{Competing interests}

The authors declare that they have no conflict of interest.

\section{Funding}

There is no funding source.

\section{Authors' contributions}

OK,ASS participated in the design of the study and performed the statistical analysis. OK conceived of the study, and participated in its design and coordination and helped to draft the manuscript. OK writing and collecting data.

All authors read and approved the final manuscript.

\section{Acknowledgements}

Not applicable.

\section{Authors' information}

1) Ozgun Karakus: Orthopedic Surgeon, Balıkesir City Hospital, Turkey.

Mail: ozgunkarakus@hotmail.com

3) Ahmet Sinan Sari: Assistant Professor of Orthopedic Surgeon, Omer Halisdemir University Hospital, Turkey. Mail: drasinansari@gmail.com

\section{References}

1. -Khan Y, Nagy MT, Malal J, et al. The painful shoulder: shoulder impingement syndrome. Open Orthop J. 2013 Sep;6:7:347-51.

2. - Armstrong JR. Excision of the acromion in treatment of the supraspinatus syndrome; report of ninety-five excisions. J Bone Joint Surg Br. 1949 Aug;31B(3):436-42.

3. -Neer CS. Anterior acromioplasty for the chronic impingement syndrome in the shoulder. 1972. J Bone Joint Surg Am. 2005 Jun;87(6):1399.

4. -Neer CS. Impingement lesions. Clin Orthop Relat Res. 1983 Mar;(173):70-7. 
5. -Yu E, Cil A, Harmsen WS, Schleck C, et al. Arthroscopy and the dramatic increase in frequency of anterior acromioplasty from 1980 to 2005: an epidemiologic study. Arthroscopy. 2010 Sep;26(9 Suppl):142-7.

6. -Ketola S, Lehtinen J, Rousi T, et al. No evidence of long-term benefits of arthroscopic acromioplasty in the treatment of shoulder impingement syndrome: Five-year results of a randomised controlled trial. Bone Joint Res.

7. . 2013 Jul 1;2(7):132-9.

8. - Flatow EL, Soslowsky LJ, Ticker JB, et al. Excursion of the rotator cuff under the acromion. Patterns of subacromial contact. Am J Sports Med Nov-Dec. 1994;22(6):779-88.

9. - AA. Romeo DW, Hang BR, Bach Jr, et al. Repair of full thickness rotator cuff tears: gender, age, and other factors affecting outcome. Clin Orthop Relat Res.1999 Oct;(367):243-55.

10. -Gill TJ, Mclrvin E, Kocher MS, et al. The relative importance of acromial morphology and age with respect to rotator cuff pathology. J Shoulder Elbow Surg Jul-Aug. 2002;11(4):327-30.

11. -Shin SJ, Oh JH, Chung SW, et al. The efficacy of acromioplasty in the arthroscopic repair of small- to mediumsized rotator cuff tears without acromial spur: prospective comparative study. Arthroscopy. 2012 May;28(5):628-35.

12. - Chahal J, Mall N, MacDonald PB, et al. The role of subacromial decompression in patients undergoing arthroscopic repair of full-thickness tears of the rotator cuff: a systematic review and meta-analysis. Arthroscopy. 2012 May;28(5):720-7.

13. -Green A, Griggs S, Labrador D. Anterior acromial anatomy: relevance to arthroscopic acromioplasty. Arthroscopy. 2004 Dec;20(10):1050-4.

14. - Blaine TA, Kim YS, Voloshin I, et al. The molecular pathophysiology of subacromial bursitis in rotator cuff disease. J Shoulder Elbow Surg Jan-Feb. 2005;14(1 Suppl S):84S-89S.

15. -McFarland EG, Maffulli N, Del Buono A, et al. Impingement is not impingement: the case for calling it "rotator cuff disease. Muscles Ligaments Tendons J. 2013 Aug;11(3):196-200. 3(.

16. - Lee TQ, Black AD, Tibone JE, et al. Release of the coracoacromial ligament can lead to glenohumeral laxity: a biomechanical study. J Shoulder Elbow Surg Jan-Feb. 2001;10(1):68-72.

17. -Su WR, Budoff JE, Luo ZP. The effect of coracoacromial ligament excision and acromioplasty on superior and anterosuperior glenohumeral stability. Arthroscopy. 2009 Jan;25(1):13-8.

18. - Gartsman GM, O'connor DP. Arthroscopic rotator cuff repair with and without arthroscopic subacromial decompression: a prospective, randomized study of one-year outcomes. J Shoulder Elbow Surg Jul-Aug. 2004;13(4):424-6.

19. - Longo UG, Berton A, Papapietro N, et al. Epidemiology, genetics and biological factors of rotator cuff tears. Med Sport Sci. 2012;57:1-9.

20. -Longo UG, Berton A, Khan WS, et al. Histopathology of rotator cuff tears. Sports Med Arthrosc Rev. 2011 Sep;19(3):227-36. 
21. -Balke $M$, Schmidt C, Dedy $N$, et al. Correlation of acromial morphology with impingement syndrome and rotator cuff tears. Acta Orthop. 2013 Apr;84(2):178-83.

22. - Papadonikolakis A, McKenna $M$, Warme $W$, et al. Published evidence relevant to the diagnosis of impingement syndrome of the shoulder. J Bone Joint Surg Am. 2011 Oct 5;93(19):1827-32.

23. -Frank JM, Chahal J, Frank RM, et al. The role of acromioplasty for rotator cuff problems. Orthop Clin North Am. 2014 Apr;45(2):219-24.

24. -Shi LL, Edwards TB. The role of acromioplasty for management of rotator cuff problems: where is the evidence. Adv Orthop. 2012;2012:467571.

25. - Matsen. FA 3rd. Open rotator cuff repair without acromioplasty. J Bone Joint Surg Am. 2009 Feb;91(2):487.

26. -Goldberg BA, Lippitt SB, Matsen FA 3rd. Improvement in comfort and function after cuff repair without acromioplasty. Clin Orthop Relat Res. 2001 Sep;(390):142-50.

27. - MacDonald P, McRae S, Leiter J, et al. Arthroscopic rotator cuff repair with and without acromioplasty in the treatment of full-thickness rotator cuff tears: a multicenter, randomized controlled trial. J Bone Joint Surg Am. 2011 Nov 2;93(21):1953-60.

28. - Milano G, Grasso A, Salvatore M, et al. Arthroscopic rotator cuff repair with and without subacromial decompression: a prospective randomized study. Arthroscopy. 2007 Jan;23(1):81-8.

29. -Ketola S, Lehtinen J, Elo P, et al. No difference in long-term development of rotator cuff rupture and muscle volumes in impingement patients with or without decompression. A randomized MRI study of 140 patients. Acta Orthop. 2016 Aug;87(4):351-5.

30. - Abrams GD, Gupta AK, Hussey KE, et al. Arthroscopic repair of full-thickness rotator cuff tears with and without Acromioplasty: randomized prospective trial with 2-year follow-up. Am J Sports Med. 2014 Jun;42(6):1296-303.

31. -Wang JC, Shapiro MS. Changes in acromial morphology with age. J Shoulder Elbow Surg Jan-Feb. 1997;6(1):55-9. 